\title{
Opportunities and Barriers to Optimal Early Breastfeeding Among Mothers Delivering at a Teaching and Referral Hospital in Uasin-Gishu County, Kenya
}

\author{
Felix Kiplagat Boor ${ }^{1 *}$ and Irene Ogada ${ }^{2}$ \\ ${ }^{1}$ Department of Foods, Nutrition, and Dietetics, University of Eastern Africa, Kenya \\ ${ }^{2}$ Department of Human Nutrition, St. Francis Xavier University, Canada
}

Submission: January 18, 2019 ; Published: January 28, 2019

*Corresponding author: Felix Kiplagat Boor, Department of Foods, Nutrition, and Dietetics, University of Eastern Africa, Kenya

Abstract

Background: Optimal early breastfeeding has been shown to benefit infants and mothers. Studies in other settings, have identified demographic and socio-economic factors such as age, employment status, and level of education as influencers of early breastfeeding.

Objective: The objective of this study was to establish the opportunities and barriers to optimal early breastfeeding among mothers who deliver at a Teaching and Referral Hospital, in Uasin-Gishu County, with the aim to inform stakeholders of areas to focus interventions.

Methods: This was a cross-sectional study, conducted among 283 mothers who had delivered at a Teaching and Referral Hospital, in UasinGishu County in the previous 72 hours. A structured researcher-administered questionnaire was used to collect data among post-partum women on aspects of early breastfeeding: time of initiation of breastfeeding, giving of colostrum, pre and post-lacteals, as well as exclusive breastfeeding. Key Informant Interviews were also conducted with health workers at the maternity ward.

Result: The identified opportunities for optimal early breastfeeding included promotion of breastfeeding immediately after postpartum, giving colostrum and not giving pre and post lacteals. The face-to-face interviews showed that about a quarter (24.0\%) of the mothers reported having encountered barriers/ challenges related to early breastfeeding. Among the 68 (24.0\%) mothers who encountered challenges, breast problems were reported by most (52.5\%). Other challenges included low milk production $(23.7 \%)$, inability to position and attach the baby $(10.2 \%)$, maternal illness $(8.5 \%)$, baby crying while breastfeeding $(3.4 \%)$, with a few $(1.7 \%)$ women reporting challenges with pumping breast milk.

Conclusions and recommendations: most of the opportunities and barriers identified were modifiable. We recommend health facilities should adress challenges faced by mothers both at the health facility and after discharge from the hospital by streangthening post-natal education.

Keywords: Opportunities; Barriers; Early breastfeeding; Optimum; Postpartum; Breast problems

\section{Background}

Optimal early breastfeeding has been shown to benefit infants and mothers. Studies in other settings, have identified demographic and socio-economic factors such as age, employment status, and level of education as influencers of early breastfeeding. In some studies done in the Middle East, demographic and socio-economic factors such as age, employment status, and level of education of the participants may influence breastfeeding. A Lebanese study reported that race, insufficient milk supply, lifestyle issues like smoking, and method of delivery, were also factors that may influence breastfeeding [1,2]. In India, some studies have shown that psychosocial and cultural barriers to early breastfeeding still exist in some communities, in spite of the fact that breastfeeding in that country is universal [3].

Factors such as skin-to-skin contact between mother and baby and vaginal delivery have benefits to successful early initiation to breastfeeding while others like lower education level, being a young mother, lower family income, have shown to impact early breastfeeding negatively in Brazil [3,4]. A study conducted in Australia by [5], also found that perceived insufficient breast milk supply was the most cited challenge among mothers, infantrelated reasons were the second, (an unsettled baby; inadequate weight gain; attachment problems; reflux, troublesome sleeping patterns and poor interest from the baby). He also reported 
that pain and discomfort associated with breastfeeding for the mother as another challenge. In Africa, a study conducted in Nigeria by [6], pointed out maternal/caregivers knowledge, attitudes, social, cultural and physiological factors as other challenges affecting mothers during early breastfeeding. A study conducted in India by [7], reported that early breastfeeding practices could be affected by limited information, the level of education and socio-economic factors.

Despite documenting the positive influence on early breastfeeding, there is need to ensure that all the 10 steps to successful breastfeeding are adhered to by both the healthcare personnel and the breastfeeding mothers during the first few days before discharge so as to minimize negative influencers to early breastfeeding. It is against this background that this study was conducted. The main objective of this study was to establish the opportunities and barriers to optimal early breastfeeding among mothers who deliver at a Teaching and Referral Hospital, in Uasin-Gishu County, with the aim to inform stakeholders of areas to focus interventions.

\section{Methods and Materials}

\section{Research design, population and location}

This was a cross-sectional involving 283 mothers aged 15-49 years who had delivered in the previous 72 hours at a Teaching and Referral Hospital in Uasin-Gishu County. The maternal facility is well established with a bed capacity of 500 beds conducting up to 12,000 deliveries per year an average of 30 births daily [8]. Mothers who delivered through cesarean section, and were too weak to respond to questions were excluded from the study. Those who declined to give informed consent were also excluded from the study.

\section{Sample size}

The sample size of 283 newborn-mother pairs which was calculated based on a standard normal deviate at $95 \%$ confidence level (1.96) was used. Mothers who initiate breastfeeding within one hour in Rift valley was estimated to be $63.7 \%$ [9], a desired level of precision of 0.05 for a target population less than 10,000 . Ten percent of the calculated sample size was added to the final sample size to cater for non-response. Two key informants (1 Nurse in charge of the maternity ward and 1 Nutritionist) were also included in the study.

\section{Sampling techniques}

The Teaching and Referral Hospital was purposively selected because it serves a large population in the North Rift, Western and Nyanza regions of Kenya and also some parts of Eastern Uganda. All mothers who met the inclusion criteria were clustered into dorms/wards before randomly selected to participate in the study, until the sample size was achieved, while the key informants were purposively selected to participate in the study since they were the most knowledgeable on early breastfeeding practices at the maternity ward having worked there for a period of more than one year and were also in charge of their respective specialties at the ward.

\section{Data collection instruments and procedures}

Validated researcher-administered questionnaire $[10,11]$ were used to conduct a onetime face to face interviews with mothers at the hospital. These elicited information on:

a) Maternal and newborn socio-economic and demographic characteristics.

b) Maternal early breastfeeding challenges.

A pre-test was conducted with 28 mothers who did not participate in the main study, this was to enhance the validity and reliability of the questionnaire. The mothers in the pretest had similar characteristics as the study participants. Data was collected twice at an interval of two days from the same participants during the pre-test and a comparison made between the responses obtained from both interviews. A correlation coefficient of $0.90(0.80-0.99 ; 95 \% \mathrm{CI})$ was achieved, which indicated adequate reliability of the questionnaire [12].

To solicit more information, two Key informant interviews (KII) were conducted with both the nutritionist and the nurse in charge of the labor ward at their respective work stations, using two pre-tested KII guides which elicited information on the early breastfeeding challenges faced by the healthcare providers and mothers delivering at the hospital.

\section{Data analysis and presentation}

Statistical Package for Social Sciences (SPSS) version 23.0 was used to analyze data, and generated the descriptive statistics which included means, frequencies, percentages, and standard deviation for demographic and socio-economic characteristics of the study participants, as well as the barriers to early initiation to breastfeeding. Logistic regression was used to determine the association between demographic and socioeconomic characteristics and the barriers to early initiation to breastfeeding. Statistical significance was set at $p<0.05$. Content analysis from the key informant interviews was conducted and transcribed verbatim by categorizing them into key predetermined themes: barriers to early initiation to breastfeeding faced by the healthcare staff and early breastfeeding challenges faced by mothers delivering at the hospital.

\section{Results}

A total of 285 mothers out of 315 who were eligible to participate in this study consented. Those who declined to participate (30mothers) were excluded, and the questionnaires administered to all the 285 mothers who were recruited to participate in the study after signing the consent form. A total of 283 questionnaires were analyzed out of the 285 questionnaires because 2 were incomplete, giving a response rate of $99.3 \%$, which is considered adequate by [13]. The qualitative data was obtained from interviewing 2 key informants using the KII guide. 


\section{Demographic and socio-economic characteristics of the participants}

Table 1: Maternal demographic and socio-economic characteristics.

\begin{tabular}{|c|c|c|}
\hline \multirow{2}{*}{ Maternal Demographic Characteristics } & \multicolumn{2}{|c|}{$\mathbf{N}=\mathbf{2 8 3}$} \\
\hline & n & $\%$ \\
\hline $15-24$ & 81 & 28.7 \\
\hline $25-34$ & 145 & 51.2 \\
\hline $35-44$ & 55 & 19.4 \\
\hline $45-49$ & 2 & 0.7 \\
\hline Total & 283 & 100 \\
\hline \multicolumn{3}{|c|}{ Marital Status of Mother } \\
\hline Married & 156 & 55.1 \\
\hline Single & 123 & 43.5 \\
\hline Separated & 4 & 1.4 \\
\hline Total & 283 & 100 \\
\hline \multicolumn{3}{|c|}{ Parity } \\
\hline $1-2$ & 181 & 181 \\
\hline $3-4$ & 69 & 69 \\
\hline More than 5 & 33 & 33 \\
\hline Total & 283 & 283 \\
\hline \multicolumn{3}{|c|}{ Level of Education } \\
\hline Completed college/university & 109 & 38.7 \\
\hline Completed Secondary & 83 & 29.4 \\
\hline Completed primary & 59 & 20.9 \\
\hline None & 31 & 11 \\
\hline Total & 283 & 100 \\
\hline \multicolumn{3}{|c|}{ Occupation of Mother } \\
\hline Housewife & 101 & 35.7 \\
\hline Self-employed & 74 & 26.1 \\
\hline Professional & 54 & 19.1 \\
\hline Student & 45 & 15.9 \\
\hline Farmer & 9 & 3.2 \\
\hline Total & 283 & 100 \\
\hline
\end{tabular}

From the study the mean age of mothers was $28.9 \pm 0.6$ years, with a range of 15-17 years from the youngest and the oldest mother (Table 1). The mothers who were between 25-34 years of age about half (51.2\%), while those who were married were slightly more than half (55.1\%) and those who had 1-2 children were $64.0 \%$. Mothers who had college or university level of education were slightly over a third (38.7\%), while those who did not have any formal education were $11 \%$. The housewives comprised of about a third (35.7\%).

The face-to-face interviews showed that about a quarter $(24.0 \%)$ of the mothers reported having encountered challenges related to early breastfeeding. Among the 68 (24.0\%) mothers who encountered challenges, breast problems were reported by most (52.5\%). These breast problems included blocked nipples, pain in one breast, and lack of milk in one breast. Other challenges included low milk production (23.7\%), inability to position and attach the baby $(10.2 \%)$, maternal illness $(8.5 \%)$, baby crying while breastfeeding (3.4\%), with a few $(1.7 \%)$ women reporting challenges with pumping breast milk (Figure 1). The Key informants corroborated the information given by the mothers, "mothers delivering via caesarean section are required to recover from surgery before breastfeeding is initiated hence experience delays in the initiation of breastfeeding due to the effect of the anesthetic drugs. Sometimes, anesthetic drugs hinder milk production, hence delaying the initiation of breastfeeding while others do not have milk at all" (KI2, 2016).

Association between maternal demographic, socio-economic status and barriers to early initiation to breastfeeding the likelihood that maternal challenges were related to maternal demographic and socio-economic characteristics was tested using logistic regression (Table 2). Mothers who were not married were two times more likely to experience challenges during early breastfeeding (OR=1.727; 95\% CI: 0.994-3.000; $\mathrm{p}=0.051$ ). Similarly, those who had not completed secondary 
education were two times more likely to experience challenges during early breastfeeding (OR=1.533; 95\% CI: 0.826-2.843; $\mathrm{p}=0.174$ ), while those who were professionals were less likely to experience challenges during early breastfeeding $(\mathrm{OR}=0.925$; 95\% CI: 0.520-1.645; $\mathrm{p}=0.79$ ).

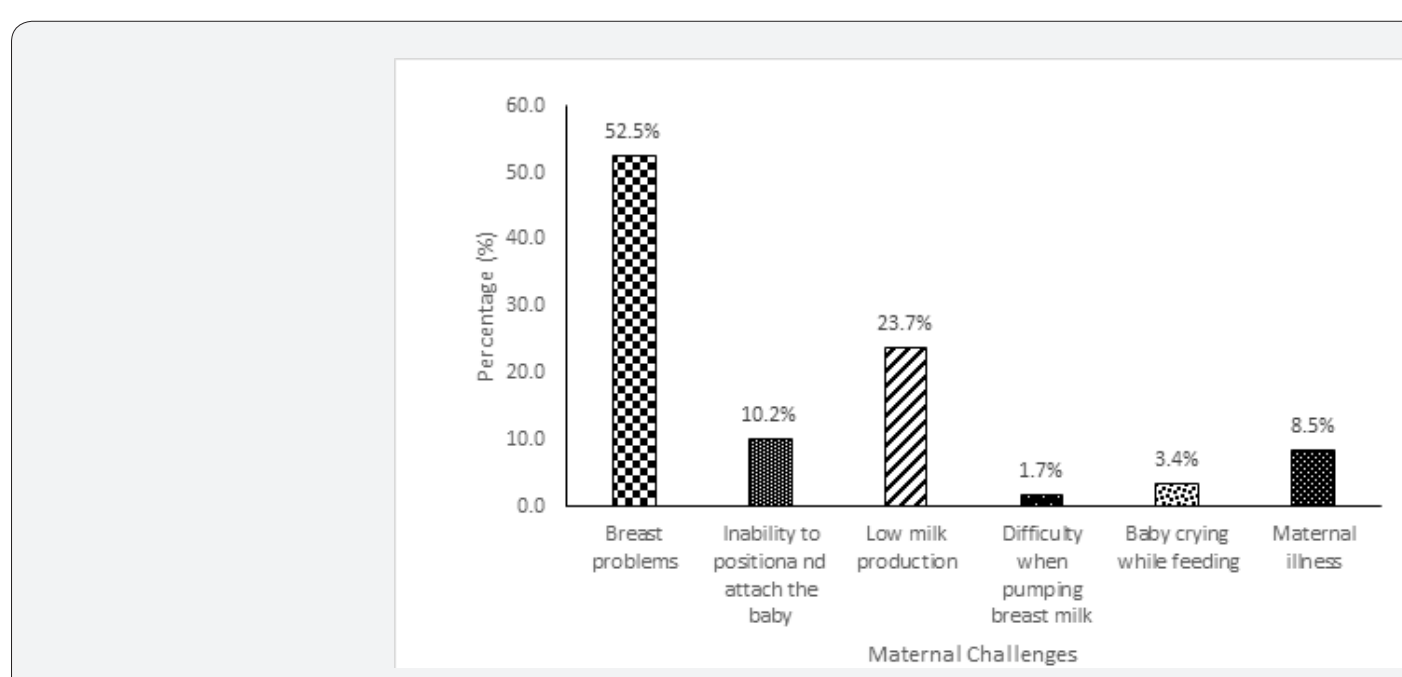

Figure 1: Barriers to early initiation to breastfeeding.

Table 2: Association between maternal demographic, socio-economic characteristics and barriers to early initiation to breastfeeding.

\begin{tabular}{|c|c|c|c|c|}
\hline \multirow{3}{*}{ Maternal Demographic and Socio-Economic Characteristics } & \multicolumn{3}{|c|}{$\mathbf{N}=\mathbf{2 8 3}$} & \multirow{3}{*}{ p-value } \\
\hline & \multirow{2}{*}{ Odds Ratio (OR) } & \multicolumn{2}{|c|}{ C.I. $(95 \%)$} & \\
\hline & & Lower Limit & Upper Limit & \\
\hline \multicolumn{5}{|c|}{ Marital Status } \\
\hline Married & 1 & & & \\
\hline Not married & 1.727 & 0.994 & 3 & 0.051 \\
\hline \multicolumn{5}{|c|}{ Level of Education } \\
\hline Completed secondary education & 1 & & & \\
\hline \multicolumn{5}{|l|}{ Not completed secondary } \\
\hline education & 1.533 & 0.826 & 2.843 & 0.174 \\
\hline \multicolumn{5}{|c|}{ Type of Occupation } \\
\hline Housewife & 1 & & & \\
\hline Professionals & 0.925 & 0.52 & 1.645 & 0.79 \\
\hline
\end{tabular}

\section{Discussion}

Findings from this study, indicated that barriers to early breastfeeding were minimal, as the majority of the mothers were practiced the recommended procedures and were knowledgeable on most aspects of early breastfeeding. Most mothers reported to have had breast problems which included blocked nipples, pain in one breast, and lack of milk in one breast. Others were low milk production (23.7\%), inability to position and attach the baby $(10.2 \%)$, maternal illness $(8.5 \%)$, baby crying while breastfeeding $(3.4 \%)$, with a few $(1.7 \%)$ women reporting challenges with pumping breast milk. However the barriers encountered were not unique to this study. In some studies done in the Middle East demographic and socioeconomic factors such as age, employment status, and level of education of the participants may influence breastfeeding [2,14]. In India, some studies have shown that psychosocial and cultural barriers to early breastfeeding still exist in some communities
[15]. Factors such as skin-to-skin contact between mother and baby, being a young mother, lower education level, lower family income, and vaginal delivery also affect successful early initiation of breastfeeding $[3,4]$. A study conducted in Australia by [5], found that insufficient breast milk supply was the most cited challenge among mothers, infant-related reasons were the second, and this included an unsettled baby; inadequate weight gain; attachment problems; reflux, troublesome sleeping patterns and poor interest from the baby. He also reported that pain and discomfort associated with breastfeeding for the mother as another challenge.

Mothers reporting not having enough milk were not unique to this study as other studies have reported that many mothers worry about their milk supply, especially in the early stages of breastfeeding, some have stopped breastfeeding because they "didn't have enough milk". But nearly all mothers do produce enough milk for their babies [16]. 
Despite few mothers reported as to have had challenges during the early breastfeeding, the few reported cases indicate an underlying problem which may affect their attitudes and practices. This in turn can affect the breastfeeding babies negatively. The adverse effects may expose a baby to increased risk of morbidity and mortality. The infants may also be susceptible to infections due to a decline in immunity. There is no relationship between maternal demographic, socio-economic characteristics and challenges during early breastfeeding.

\section{Conclusion}

Despite most mothers not reporting challenges in breastfeeding in the first few days after delivery a few reported to have encountered challenges which act as barriers to successful breastfeeding. These included problems with the breast (pain while breastfeeding, blocked nipples, etc.), low milk production, and not being able to position and attach the baby correctly, maternal illness, and baby crying while breastfeeding. Problems like pain while breastfeeding, blocked nipples have a negative effect to mothers because it affects milk production and stresses them thinking that their babies are not getting enough milk which leads them to start using post-lacteals. The identified opportunities for optimal early breastfeeding which included promotion of breastfeeding immediately after postpartum, giving colostrum and not giving pre and post lacteals were reported to be good.

\section{Recommendation}

To minimize the barriers to early initiation to breastfeeding there is need to ensure that both the healthcare personnel and the breastfeeding mothers adhere to all the ten steps to successful breastfeeding [17] during the first few days before discharge. Problems like pain while breastfeeding, blocked nipples should be identified early enough by the healthcare personel to minimize the negative effect to mothers and enable them relax, which will help in milk production.

\section{Acknowledgement}

We acknowledge management of the Teaching and Referral Hospital management for allowing us to use their facility in conducting this study not forgetting the study participants who gave consent and participated in the study. The study was funded by the authors.

\section{References}

1. Obilade TT (2015) The Knowledge, Attitude and Practice of Exclusive Breastfeeding among Mothers in Two Semi-Urban Areas around a Baby Friendly Hospital Initiative (BFHI) designated hospital in Lagos State, Nigeria. Int Arch Med.
2. Thulier D, Mercer J (2009) Variables associated with breastfeeding duration. J Obstet Gynecol Neonatal Nurs 38(3): 259-268.

3. Silveira RBDA, Albernaz E, Zuccheto LM (2008) Fatores associados aoinício da amamentação emuma cidade dosul do Brasil. Rev Bras Saúde Matern Infant 8(1): 35-43.

4. Vieira TO, Vieira GO, Giugliani ERJ, Mendes CMC, Martins CC, et al. (2010) Determinants of breastfeeding initiation within the first hour of life in a Brazilian population: cross-sectional study. BMC Public Health 10(1): 760.

5. Hauck YL, Fenwick J, Dhaliwal SS, Butt J (2011) A Western Australian survey of breastfeeding initiation, prevalence and early cessation patterns. Matern Child Health J 15(2): 260-268.

6. Ogunba B, Agwo E (2014) Knowledge, attitude and intending practices of female undergraduates about breastfeeding. African J food, Agric Nutr Dev 14(4).

7. Shwetal B, Pooja P, Neha K, Amit D, Rahul P, et al. (2012) Original Article Knowledge, Attitude and Practice of Postnatal Mothers for Early Initiation of Breast Feeding in the Obstetric Wards of a 3(2): 305-309.

8. Indiana Institute for Global Health (2015) Riley Mother \& Baby Hospital [Internet]. Maternal \& Child Health.

9. Kenya Demographic Health Survey (2010) Kenya Demigraphic Health Survey, ICF Macro, Kenya.

10. Ochola SA (2008) Evaluation of two counseling strategies promoting exclusive breast feeding among HIV-negative mothers in Kibera slum, Nairobi, Kenya: A randomized controlled trial [Internet]. [Stellenbosch]: Stellenbosch University, South Africa.

11. Ogada IA (2014) Effectiveness of couple counselling versus maternal counselling in promoting exclusive breast feeding: A randomised controlled trial in Nyando district, Kenya. Kenyatta University thesis repository. Kenyyatta University, Kenya.

12. Murphy KR, Davidshofer CO (2005) Psychological testing: principles and applications. In: ( $6^{\text {th }}$ edn), Pearson Prentice Hall, USA, p. 613.

13. Fincham JE (2008) Response rates and responsiveness for surveys, standards, and the Journal. Am J Pharm Educ 72(2): 43.

14. Nabulsi M (2011) Why are breastfeeding rates low in Lebanon? a qualitative study. BMC Pediatr 11(1): 75.

15. Garg R, Deepti S, Padda A, Singh T (2010) Breastfeeding knowledge and practices among rural women of punjab, India: a community-based study. Breastfeed Med 5(6): 303-307.

16. The Royal womens hospital (2015) Breastfeeding-Low milk supply.

17. Unicef Who (2009) Baby Friendly Hospital Initiative. Revised, Updated and Expanded for Integrated Care, p. 876. 
(C) (P) This work is licensed under Creative

(C) Commons Attribution 4.0 License

BY DOI: 10.19080/JGWH.2019.13.555875
Your next submission with Juniper Publishers will reach you the below assets

- Quality Editorial service

- Swift Peer Review

- Reprints availability

- E-prints Service

- Manuscript Podcast for convenient understanding

- Global attainment for your research

- Manuscript accessibility in different formats ( Pdf, E-pub, Full Text, Audio)

- Unceasing customer service

Track the below URL for one-step submission - https://juniperpublishers.com/online-submission.php 